\title{
Fabrication and performance of fly ash granule filter for trapping gaseous cesium
}

Jang Jin Park,
Jin Myung Shin,
Jae Hwan Yang,
Young Hee Baek,
Geun Il Park

\begin{abstract}
Although a disk-type fly ash filter has shown a good performance in trapping gaseous cesium, it has difficulty in charging filters into a filter container and discharging waste filters containing radioactive cesium from a container by remote action. To solve the difficulty of the disk-type fly ash filter, five types of granule filters, including a ball type, tube type, and sponge-structure type have been made. Among them, the best filter type was chosen through simple crucible tests. The five types of granule filters packed into containers were loaded into five alumina crucibles of $50 \mathrm{cc}$. Five grams of $\mathrm{CsNO}_{3}$ was used as a gaseous cesium source. They were then placed in a muffle furnace and heated to $900^{\circ} \mathrm{C}$ and maintained for 2 hours. After the experiment, the weights of the cesium trapped filters were measured. Among the five types of granule filters, the sponge-structure type granule filter was the best, which has the highest trapping capacity of cesium. Its capacity is 0.42 g-Cs/g-filter. The chosen sponge-structure type granule filters and disk-type filters have been tested using a two-zone tube furnace. Cs volatilization and Cs trapping zones were maintained at 900 and $1000^{\circ} \mathrm{C}$, respectively. Sixteen grams of $\mathrm{CsNO}_{3}$ was used as a gaseous cesium source. The cesium trapping profile of the sponge-structure type granule filters was almost similar to that of the disk-type fly ash filters. For both cases, cesium was successfully trapped within the third filter.
\end{abstract}

Key words: fabrication $\bullet$ gaseous cesium $\bullet$ granule filters $\bullet$ performance test $\bullet$ pyroprocessing $\bullet$ trapping

J. J. Park ${ }^{\bowtie}$, J. M. Shin, J. H. Yang, Y. H. Baek, G. I. Park Nuclear Fuel Cycle Process Development Division, Korea Atomic Energy Research Institute (KAERI), Daeduk-daero 989-111, Yuseong-gu, Daejeon 305-353, Republic of Korea, Tel.: +82 42868 8017, Fax: +82 42868 2043,

E-mail: jjpark@kaeri.re.kr

Received: 24 September 2014

Accepted: 20 May 2015

\section{Introduction}

KAERI has developed a pyroprocessing technology for spent PWR fuel. KAERI pyroprocessing process consists of a decladding process, high-temperature voloxidation process, oxide reduction process, electrorefining process, and electrowinning process [1]. From the decladding and high-temperature voloxidation processes, various kinds of nuclides can be volatilized. These are semivolatile nuclides such as $\mathrm{Cs}$, Tc, and I, and volatile nuclides such as $\mathrm{Kr}, \mathrm{Xe}$, $\mathrm{C}-14$, and H-3 [2]. Among these nuclides, cesium is very important. Cs is a semivolatile fission product, highly radioactive and highly decay heating element [3]. The half-life of ${ }^{137} \mathrm{Cs}$ is $30.2 \mathrm{y}$. Cs is very leachable under disposal environments. Cs is expected to volatize as various gaseous forms of $\mathrm{Cs}_{2} \mathrm{O}, \mathrm{Cs}_{2} \mathrm{O}_{3}$, and CsI during the high-temperature voloxidation process of spent PWR fuel [4].

There are several methods in trapping gaseous cesium such as condensation, chemical fixation. In order to trap gaseous Cs, KAERI has developed a chemical fixation method. KAERI has used fly ash powder, which is a byproduct from coal-fired power plant and kind of aluminosilicate material $[5,6]$. Until now, KAERI has manufactured disk-type fly ash filters from fly ash slip solution and polyurethane sponge. 
However, although disk-type fly ash filters have shown a good performance in trapping gaseous cesium [5-7], it has difficulty in charging filters into a filter container and discharging filters from a container by remote action. Waste filters containing radioactive cesium have highly radioactive and decay heating. Thus, they have to be handled within a hot-cell by special tools such as manipulators. If we can make a granule-type fly ash filter, we can reduce the charging efforts of a fly ash filter into a container and the discharging efforts of fly ash filters from a container.

In this paper, five types of granule filters, including a ball type, tube type, and sponge-structure type have been made. Among them, the best granule filter type was chosen through simple crucible tests. Next, the trapping performance of the chosen best granule filter was compared with that of disk-type filter in two-zone furnace.

\section{Necessities of granule filter}

A disk-type filter needs a lot of effort in sealing between the disk-type filters and filter container wall for charging the filters into a filter container. There are difficulties in discharging disk-type filters from a container by remote action for making waste forms (waste filters containing radioactive Cs are highly radioactive and decay heating). This requires an additional raw crushing process for improving the mixing efficiency of the filter material and glass frits in the manufacturing waste forms. Meanwhile, a granule filter has no sealing problem between container wall and filters. It is easy in charging and discharging the filter material into/from the container. Even without a raw crushing process, it is easy to mix the glass frits and the granule filter material when making the waste forms.

\section{Requirements of granule filter}

Granule filters should have an efficient structure for a high-temperature gas-solid reaction. That is, it should not have closed pores but open pores for the efficient contact between gaseous cesium and the filter material. In addition, it should have structural soundness even at a high temperature of $1000^{\circ} \mathrm{C}$. The reaction products (e.g., pollucite) of gaseous cesium and fly ash [5-7] should not break away from the filter body. It should have strength handling before and after the trapping operation. It should have a proper granule size, density, and porosity.

\section{Fabrication experiment of fly ash granule filter}

Five types of granule filters have been made. Bulk density, skeleton density, and porosity of fabricated granule samples were measured. Skeleton density and porosity were measured by the liquid displacement method [8]. Since granule samples were not dissolved in distilled water, distilled water was used as measurement liquid. In order to observe surface of granule samples, a microscope (CAMSCOPE-SV32, Sometech Inc.) was used.

Granule sample 1 was made without using a pore former. Fly ash paste was made with fly ash powder and a PVA (polyvinyl alcohol) solution. Fly ash balls of $\sim 5 \mathrm{~mm}$ were made by scrubbing paste with hands. They were then dried under room temperature and heated at $1250^{\circ} \mathrm{C}$. The bulk density of the granule sample 1 was $0.98 \mathrm{~g} / \mathrm{cm}^{3}$. The skeleton density of sample 1 was $1.8 \mathrm{~g} / \mathrm{cm}^{3}$ and the porosity was $37 \%$. Granule sample 2 was made from the paste (sample 1 paste + pore former (active carbon particle)). Granule sample 2 was also dried under room temperature and heated at $1250^{\circ} \mathrm{C}$. The bulk density of granule sample 2 was $0.54 \mathrm{~g} / \mathrm{cm}^{3}$. The skeleton density was $0.84 \mathrm{~g} / \mathrm{cm}^{3}$. The porosity was $65.3 \%$. The porosity of sample 2 was larger than that of sample 1 . In the case of granule sample 3, polyethylene particles were used as the pore former. Granule sample 3 was also dried under room temperature and heated at $1250^{\circ} \mathrm{C}$. The bulk density of granule sample 3 was $0.47 \mathrm{~g} / \mathrm{cm}^{3}$. The skeleton was $0.87 \mathrm{~g} / \mathrm{cm}^{3}$. The porosity was $62.8 \%$. The porosity of sample 3 was larger than that of sample 1 and was similar to that of sample 2 . The tube type granule sample 4 was made to increase gas-solid contact efficiency. Strings were immersed in a slip solution including active carbon particles. Strings added with a slip were dried and immersed again in the slip solution. This was repeated several times. They were then cut by $\sim 5 \mathrm{~mm}$ and heated at $1250^{\circ} \mathrm{C}$. The bulk density of granule sample 4 was $0.76 \mathrm{~g} / \mathrm{cm}^{3}$. The skeleton density was $1.21 \mathrm{~g} / \mathrm{cm}^{3}$.

Granule sample 5 was made to have a sponge structure like that of a disk-type filter. They were a cubic type. Each side was $\sim 5 \mathrm{~mm}$. They were made by using a polyurethane sponge of $\sim 5 \mathrm{~mm}$ on each side. The manufacturing method is similar to that of a disk-type filter [2]. The bulk density of granule sample 5 was $0.32 \mathrm{~g} / \mathrm{cm}^{3}$. The skeleton density was $0.92 \mathrm{~g} / \mathrm{cm}^{3}$.

Table 1 shows summarized results from sample 1 to sample 5 including the overall granule view, magnified granule view $(\times 5)$, surface view $(\times 25)$, and physical properties. For comparison, the referred disk-type filter was also shown in Table 1 . As can be seen, the pore structure of granule sample 5 is similar to that of the referred disk-type filter. Bulk density of sample 5 was $0.32 \mathrm{~g} / \mathrm{cm}^{3}$ and that of disk filter was $0.51 \mathrm{~g} / \mathrm{cm}^{3}$. Bulk density of granule sample 5 was lower than that of disk-type filter due to packing characteristics of granules.

\section{Crucible furnace test}

Five types of granule filters and disk type filter were tested using a muffle furnace and alumina crucibles (50 cc). Five grams of $\mathrm{CsNO}_{3}$ as the cesium source was used. Each sample was heated under an air atmosphere at $900^{\circ} \mathrm{C}$. The experimental results of the crucible test are summarized in Table 2. Images before and after testing and the trapping quantity are shown. The trapping quantity of granule sample 
Table 1. Fabricated granule samples and their physical properties

\begin{tabular}{|c|c|c|c|c|}
\hline & Overall view & Enlarged view & Surface view & Physical property \\
\hline Sample 1 & & & & $\begin{array}{l}\text { Bulk density: } 0.98 \mathrm{~g} / \mathrm{cm}^{3} \\
\text { Skeleton density: } 1.8 \mathrm{~g} / \mathrm{cm}^{3} \\
\text { Porosity: } 37 \% \\
\text { Pore former: No }\end{array}$ \\
\hline Sample 2 & & $5 \mathrm{~mm}$ & & $\begin{array}{c}\text { Bulk density: } 0.54 \mathrm{~g} / \mathrm{cm}^{3} \\
\text { Skeleton density: } 0.84 \mathrm{~g} / \mathrm{cm}^{3} \\
\text { Porosity: } 65.3 \% \\
\text { Pore former: active carbon }\end{array}$ \\
\hline Sample 3 & & $5 \mathrm{~mm}$ & & $\begin{array}{c}\text { Bulk density: } 0.47 \mathrm{~g} / \mathrm{cm}^{3} \\
\text { Skeleton density: } 0.87 \mathrm{~g} / \mathrm{cm}^{3} \\
\text { Porosity: } 62.8 \% \\
\text { Pore former: polyethylene }\end{array}$ \\
\hline Sample 4 & & & & $\begin{array}{c}\text { Bulk density: } 0.76 \mathrm{~g} / \mathrm{cm}^{3} \\
\text { Skeleton density: } 1.21 \mathrm{~g} / \mathrm{cm}^{3} \\
\text { Porosity: } 58.6 \% \\
\text { Pore former: string and active carbon }\end{array}$ \\
\hline Sample 5 & & & & $\begin{array}{c}\text { Bulk density: } 0.32 \mathrm{~g} / \mathrm{cm}^{3} \\
\text { Skeleton density: } 0.92 \mathrm{~g} / \mathrm{cm}^{3} \\
\text { Porosity: } 72.4 \% \\
\text { Pore former: sponge }\end{array}$ \\
\hline Disk-type filter & & & & $\begin{array}{c}\text { Bulk density: } 0.51 \mathrm{~g} / \mathrm{cm}^{3} \\
\text { Skeleton density: } 0.81 \mathrm{~g} / \mathrm{cm}^{3} \\
\text { Porosity: } 69.7 \% \\
\text { Pore former: sponge }\end{array}$ \\
\hline
\end{tabular}

1 was $0.09 \mathrm{~g}$-Cs/g-filter. Those of granule samples 2, 3, 4, 5, and disk-type filter are $0.33 \mathrm{~g}$-Cs/g-filter, $0.33 \mathrm{~g}$-Cs/g-filter, $0.30 \mathrm{~g}$-Cs/g-filter, $0.42 \mathrm{~g}$-Cs/ g-filter, and $0.63 \mathrm{~g}-\mathrm{Cs} / \mathrm{g}$-filter, respectively. Among the granule samples, sample 5 (sponge structure) has the highest trapping value $(0.42 \mathrm{~g}-\mathrm{Cs} / \mathrm{g}$-filter $)$. This might mean that a sponge structure granule having the highest gas-solid contact efficiency shows the highest trapping quantity. In addition, the sponge structure of a granule is the most proper structure for trapping gaseous cesium among various granule structures.

However, the trapping quantity of sample 5 is $\sim 67 \%$ of that of the disk filter. This means that the gas-solid contact efficiency of the granule filter is lower than that of the disk-type filter. Therefore, it should be noted that this difference of the trapping efficiency would be overcome within the operating condition (flow rate, operating temperature, atmosphere, etc.) of the off-gas trapping equipment.

\section{Two-zone furnace test}

Among the five granule samples, the granule sample 5 shows the best experimental result. Therefore, the granule sample 5 and referred disk-type filter were used for the two-zone furnace test. The inactive two-zone furnace test has been used for developing off-gas filters instead of active hot-cell test [5-7]. The two-zone furnace shown in Fig. 1 has an alumina tube of $5 \mathrm{~cm}$ (inside diameter) and $1.2 \mathrm{~m}$ (length). It consists of a Cs volatilization zone and Cs trapping zone. Sixteen grams of $\mathrm{CsNO}_{3}$ was used as the Cs source. Sixteen grams of $\mathrm{CsNO}_{3}$ was calculated to be equivalent to $2.7 \mathrm{~kg}$ of spent PWR fuel (initial U-235 enrichment $4.5 \%$, burnup $55000 \mathrm{MWD} / \mathrm{MTU}$, cooling time of $10 \mathrm{y}$ ) by the ORIGEN-ARP code. Ar gas was used as a carrier gas. The flow rate was $2.5 \mathrm{l} / \mathrm{min}$. The superficial gas velocity was $\sim 10 \mathrm{~cm} / \mathrm{s}$ at $1000^{\circ} \mathrm{C}$. Cs volatilization and Cs trapping zones were maintained at 900 and $1000^{\circ} \mathrm{C}$, respectively.

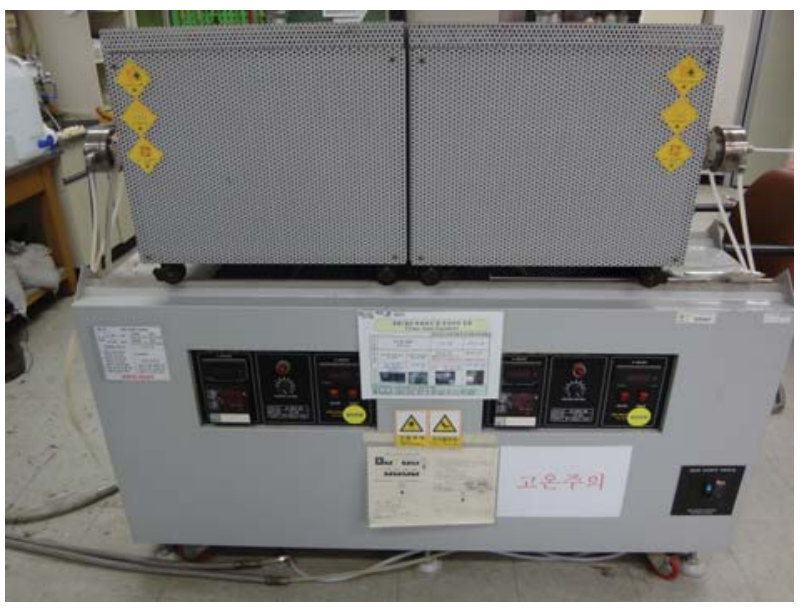

Fig. 1. Two-zone tube furnace. 
Table 2. Preliminary crucible tests of granule samples and disk-type filter

\begin{tabular}{|c|c|c|c|}
\hline & Before test & After test & Trapping quantity \\
\hline Sample 1 & & & $0.09 \mathrm{~g}-\mathrm{Cs} / \mathrm{g}$-filter \\
\hline Sample 2 & & & 0.33 g-Cs/g-filter \\
\hline Sample 3 & & & 0.33 g-Cs/g-filter \\
\hline Sample 4 & & & 0.30 g-Cs/g-filter \\
\hline Sample 5 & & & $0.42 \mathrm{~g}$-Cs/g-filter \\
\hline Disk-type filter & & & 0.63 g-Cs/g-filter \\
\hline
\end{tabular}

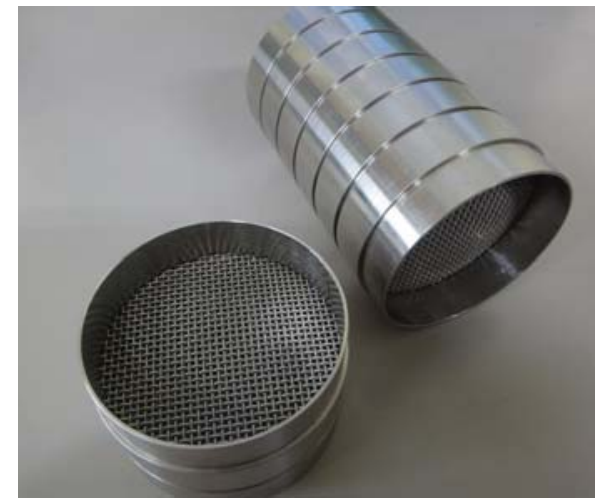

Fig. 2. Ring container for granule experiment.

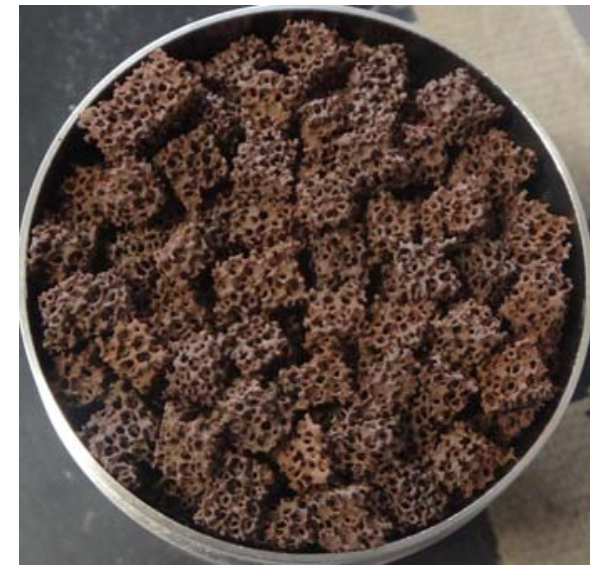

Fig. 3. Fly ash granules.
For the experiment of the granule samples, special ring containers were made as shown in Fig. 2. A sheet of a 30 mesh sieve was attached to a ring container in the order for the granules not to be squeezed out from a certain ring container. The ring container and sieve were made of SUS 304. Ten ring containers were used. $4.9 \mathrm{~g}$ of granules per ring container was used. Before the experiment, the granule sample (no. 5) in a ring container is shown in Fig. 3. An alumina sheet was used to seal the disk filters and alumina tube. In the case of the disk filter experiment, ten filters were also used. A filter weight was approx. $5 \mathrm{~g}$. The diameter of disk filter was $46 \mathrm{~mm}$ and has 12 pores per linear centimeter. A photograph of the disk-type filter is shown in

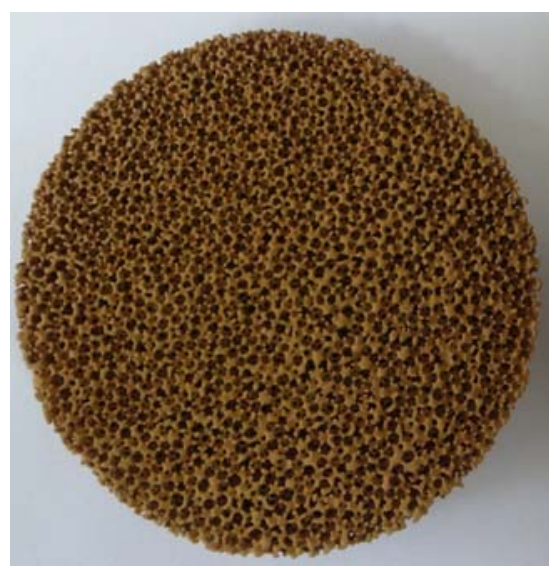

Fig. 4. Disk-type fly ash filter. 


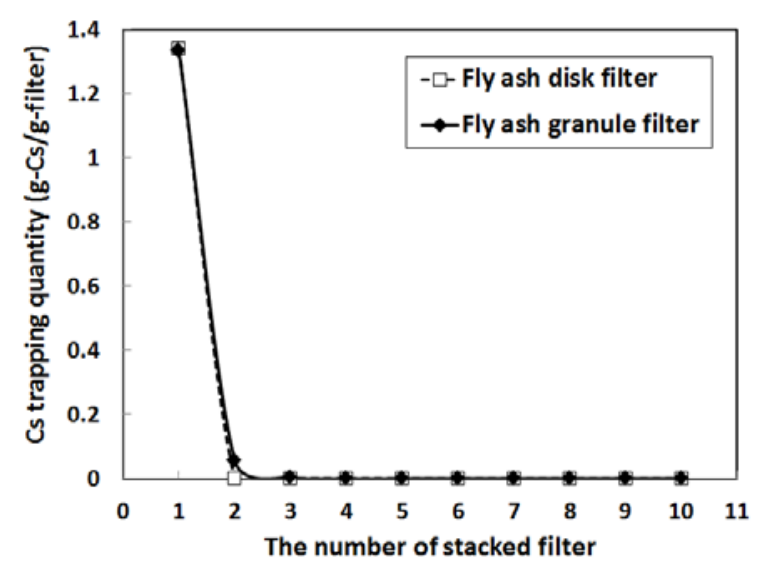

Fig. 5. Cesium trapping profiles of granule (sample 5) and disk filters.

Fig. 4. The operating conditions were the same as in the granule experiment. The alumina sheet was also used to seal the ring containers and alumina tube.

The experimental results are shown in Fig. 5. As shown in Fig. 5, Cs was trapped efficiently within the third filter for both the disk-type and granule filters. The trapping quantity was obtained from the weight measurement. The trapping quantity of the first disk-type filter was $1.35 \mathrm{~g}$-Cs/g-filter and that of the granule filter was $1.34 \mathrm{~g}-\mathrm{Cs} / \mathrm{g}$-filter. The two values were almost the same. In addition, trapping quantity profiles of the disk-type and granule filters were

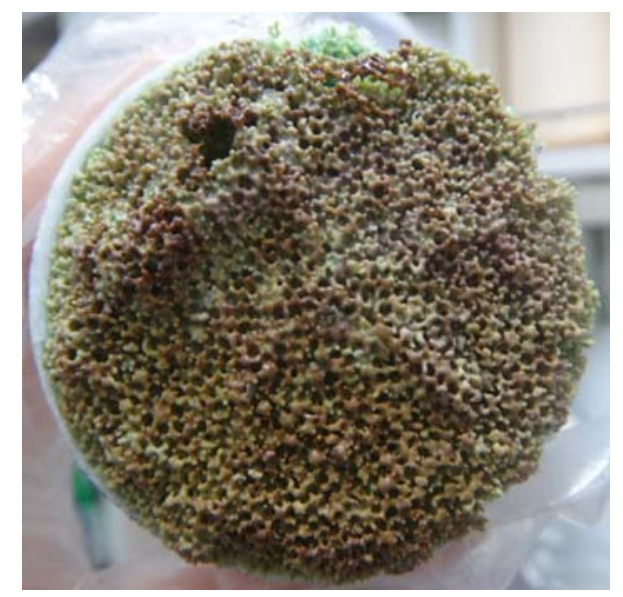

Fig. 6. The first disk-type filter after trapping.

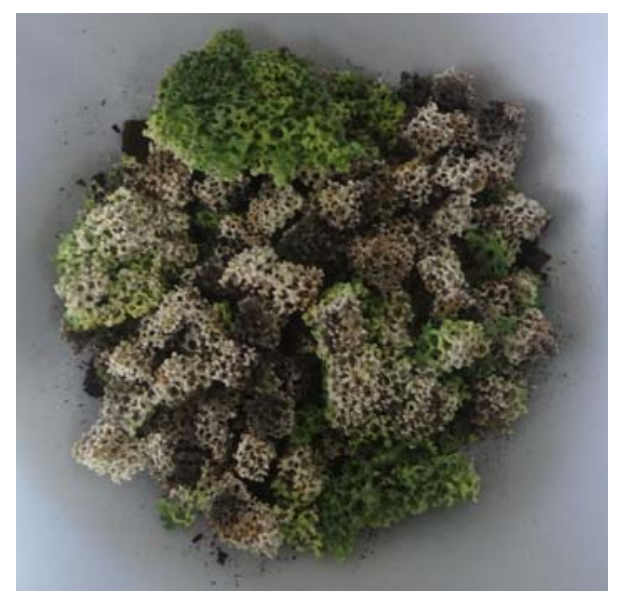

Fig. 7. The first granule filter of sponge structure (sample 5) after trapping. similar to each other. From these facts, the trapping efficiency of granule filter is expected to be similar to that of the disk-type filter within this experimental condition. It is therefore believed that the granule filter can be used instead of the disk-type filter under such experimental conditions. The first disk-type filter and first granule filter after the experiments are shown in Figs. 6 and 7, respectively. The exact results of the granule filter performance would appear after the hot experiment. In the near future, a hot experiment on a granule filter is going to be carried out in the DFDF hot-cell at KAERI.

\section{Summary}

To solve problems of a disk-type filter, five types of fly ash granule filter ( 3 ball types, 1 pipe type, 1 sponge structure type) were fabricated and their physical properties were measured. To choose the best granule, crucible tests were carried out using 5 granule samples and the referred disk-type filter. Among them, a granule filter of sponge structure had the best trapping capacity. To compare the granule filter performance with a disk filter performance, two zone furnace tests were carried out. From the two-zone furnace test, all cesium was trapped within the third filter for both cases of the sponge-structure granule filter and disk-type filter. The trapping quantity profile of the granule filter was very similar to that of the disk-type filter. Therefore, a granule filter can be used instead of a disk-type filter within this experimental condition. In the near future, a hot experiment on a granule filter is going to be carried out in the DFDF hot-cell at KAERI.

Acknowledgment. This project has been carried out under the Nuclear R\&D Programme by the Korean Ministry of Science, ICT, and Future Planning.

\section{References}

1. Park, J. J., Shin, J. M., Park, G. I., Lee, J. W., \& Song, K. C. (2009). An advanced voloxidation process at KAERI. In Global 2009, 6-11 September (Paper 9196). Paris, France.

2. Lee, H., Park, G. I., Kang, K. H., Hur, J. M., Kim, J. G., Ahn, D. H., Cho, Y. Z., \& Kim, E. H. (2011). Pyro-processing technology development at KAERI. Nucl. Eng. Technol., 43, 317-328.

3. Park, J. J., Park, C. J., Chun, J. I., Lee, J. W., Shin, J. M., Park, G. I., \& Song, K. C. (2008). Evaluation of the effects of the advanced voloxidation process on pyro-processing. I. Radiation and decay heat analysis of the advanced voloxidation process. Daejeon: KAERI. (KAERI/TR-3622/2008).

4. Jeon, M. K., Shin, J. M., Park, J. J., \& Park, G. I. (2012). Simulation of Cs behavior during the high temperature voloxidation process using the HSC chemistry code. J. Nucl. Mater., 430, 37-43.

5. Shin, J. M., \& Park, J. J. (2001). Trapping characteristics of cesium in off-gas stream using fly ash filter. Korean J. Chem. Eng., 18, 1010-1014.

6. Shin, J. M., Kim, K. Y., Park, J. J., \& Shin, S. W. (2005). Trapping characteristics for various cesium 
compounds by fly ash filter. J. Korean Soc. Waste Manage., 22(1), 27-39.

7. Shin, J. M., Park, J. J., Song, K. C., \& Kim, J. H. (2009). Trapping behavior of gaseous cesium by fly ash filters. Appl. Radiat. Isot., 67, 1534-1539.
8. Okuyama, K., \& Kousaka, Y. (1991). Particle density. In K. Iinoya, K. Gotoh \& K. Higashitani (Eds.), Powder technology handbook (pp. 35-40). New York: Marcel Dekker, Inc. 